\title{
Improvement of Nocturnal Cluster Headache after Continuous Positive Airway Pressure Therapy in a Patient with Severe Obstructive Sleep Apnea
}

\author{
Min-Jun Song, Soo-Jin Cho, Hee-Jin Im \\ Department of Neurology, Dongtan Sacred Heart Hospital, Hallym University Medical Center, Hwaseong, Korea
}

\author{
Received November 11, 2020 \\ Revised December 8, 2020 \\ Accepted December 24, 2020 \\ Address for correspondence \\ Hee-Jin Im, MD, PhD \\ Department of Neurology, \\ Dongtan Sacred Heart Hospital, \\ Hallym University \\ Medical Center, \\ 7 Keunjaebong-gil \\ Hwaseong 18450, Korea \\ Tel: +82-31-8680-3185 \\ Fax: $+82-31-8680-2317$ \\ E-mail: coolere@naver.com
}

\begin{abstract}
The relationship between cluster headache $(\mathrm{CH})$ and sleep has been demonstrated. A 60-year-old man who suffered from refractory $\mathrm{CH}$ that occurred exclusively at night, complained of sleep fragmentation. Polysomnography revealed severe obstructive apnea with deep desaturation and sleep fragmentation every 2 hours due to cyclic pain. Three months of successful continuous positive airway therapy dramatically improved both headache intensity and frequency, as well as sleep apnea. This case suggests the significance of comorbid OSA when managing patients with $\mathrm{CH}$ or primary headaches with nocturnal tendencies.
\end{abstract}

J Sleep Med 2021;18(1):55-57

Key Words: Cluster headache, Obstructive sleep apnea, Continuous positive airway pressure.

\section{Introduction}

Cluster headaches $(\mathrm{CH})$ are one of the most painful primary headache syndrome and so-called sleep-related headaches in addition to hypnic headache and migraine. $\mathrm{CH}$ has chronobiological properties and often occur with cyclicity and frequency of cluster period onset. The pathophysiology of $\mathrm{CH}$ includes hypoxia during active cluster trigger headaches and they are known to respond well to oxygen supplement during active periods of headache. Obstructive sleep apnea (OSA), one of the most common sleep disorders shares pathophysiology of recurrent hypoxia due to upper airway collapse. We report an interesting case of nocturnal $\mathrm{CH}$ with a dramatic response to continuous positive airway therapy (CPAP).

\section{Case Report}

A 60-year-old man visited a headache clinic for daily nocturnal headache and sleep fragmentation over the course of 3 years. The nature of the headaches was lancinating around the

This is an Open Access article distributed under the terms of the Creative Commons Attribution Non-Commercial License (https://creativecommons.org/licenses/by-nc/4.0) which permits unrestricted non-commercial use, distribution, and reproduction in any medium, provided the original work is properly cited. left periorbital area with severe intensity, and accompanied by ipsilateral lacrimation. The headache attacks lasted about 20 minutes and occurred every 2 hours, exclusively during sleep. These led him to wake up every 2 to 3 hours every night due to pain. The nocturnal headaches were not remitted by either 3 preventive medications including verapamil $240 \mathrm{mg}$ per day, gabapentin $600 \mathrm{mg}$ per day, valproic acid $600 \mathrm{mg}$ per day or acute management by sumatriptan for 3 months. The diagnosis was refractory chronic $\mathrm{CH}$ by the third edition of the International Classification of Headache Disorders and the European Headache Federation criteria which require at least three severe attacks per week despite at least three preventive treatments. ${ }^{1,2} \mathrm{He}$ also complained of sleep apnea and was taking antihypertensive medication. A neurological examination and brain CT angiography revealed normal. Upon physical examination, the modified Mallampatti grade of the patient was grade 3; the body mass index was $26.0 \mathrm{~kg} / \mathrm{m}^{2}(170 \mathrm{~cm} / 75 \mathrm{~kg})$; and neck circumference was $43 \mathrm{~cm}$. The Insomnia Severity Index (ISI) was 19 and the STOP-BANG score for screening sleep breathing disorders was 6 , indicating a high risk of the presence of OSA. A laboratory full-night polysomnography was then performed. The results showed that the patient had position-dependent severe OSA, with an apnea-hypopnea index 


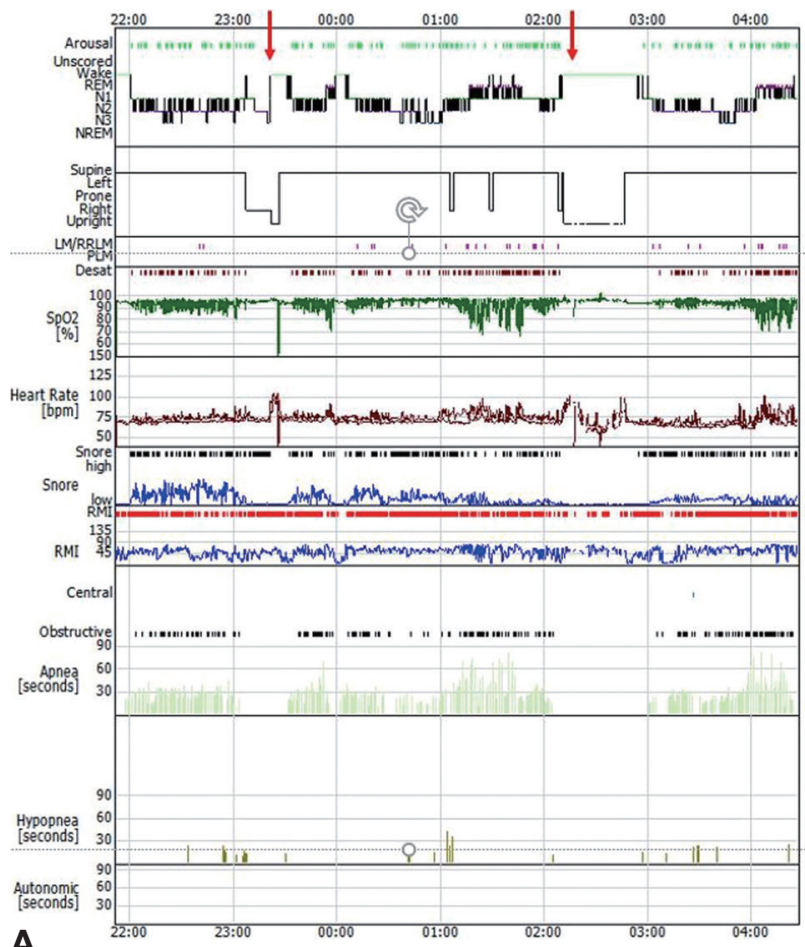

A

Figure 1. Polysomnographic hypnograms during the diagnostic study and CPAP titration study. (A) Diagnostic full-night study, arrows: awakening due to severe headache. (B) CPAP titration study. CPAP: continuous positive airway pressure.

(AHI) of 53.3/h. Not only the frequency, but also the intensity of the sleep apnea was severe enough that the minimum oxygen saturation was $69 \%$ and the longest apnea duration was 84.8 seconds. For about 6.5 hours of total sleep recording time, the patient woke up two times, at 11:21 PM and 02:10 AM, because of severe headache. He had to take sumatriptan to relieve the pain. The patient's headaches were cyclic during the night, one of the most severe periods for sleep apnea period and desaturation is shown in the polysomnographic hypnogram (Fig. $1 \mathrm{~A}$, arrows). Through the subsequent in laboratory CPAP titration study, we decided that the optimal pressure to treat sleep apnea would be $5 \mathrm{~cm} \mathrm{H}_{2} \mathrm{O}$. During the titration study, the patient remained very satisfied and experienced a peaceful night of sleep, without waking up from headaches for the first time in a few years (Fig. 1B). After CPAP therapy for 3 months, with an average usuage of 4.5 hours per night, the AHI of the patient almost completely improved to $8.8 / \mathrm{h}$. The frequency and intensity of his headaches were dramatically improved (from 29 to 10 days per month and on the visual analogue scale 8 to 3 ), and he stopped taking any preventive headache medication (Fig. 2). At nine-month follow-up after CPAP treatment, the $\mathrm{CH}$ of the patient were still nearly completely resolved with nighttime CPAP alone. The residual AHI was $7.9 / \mathrm{h}$, with 4.5 hours of average use, and the adherence to CPAP was $91.5 \%$.
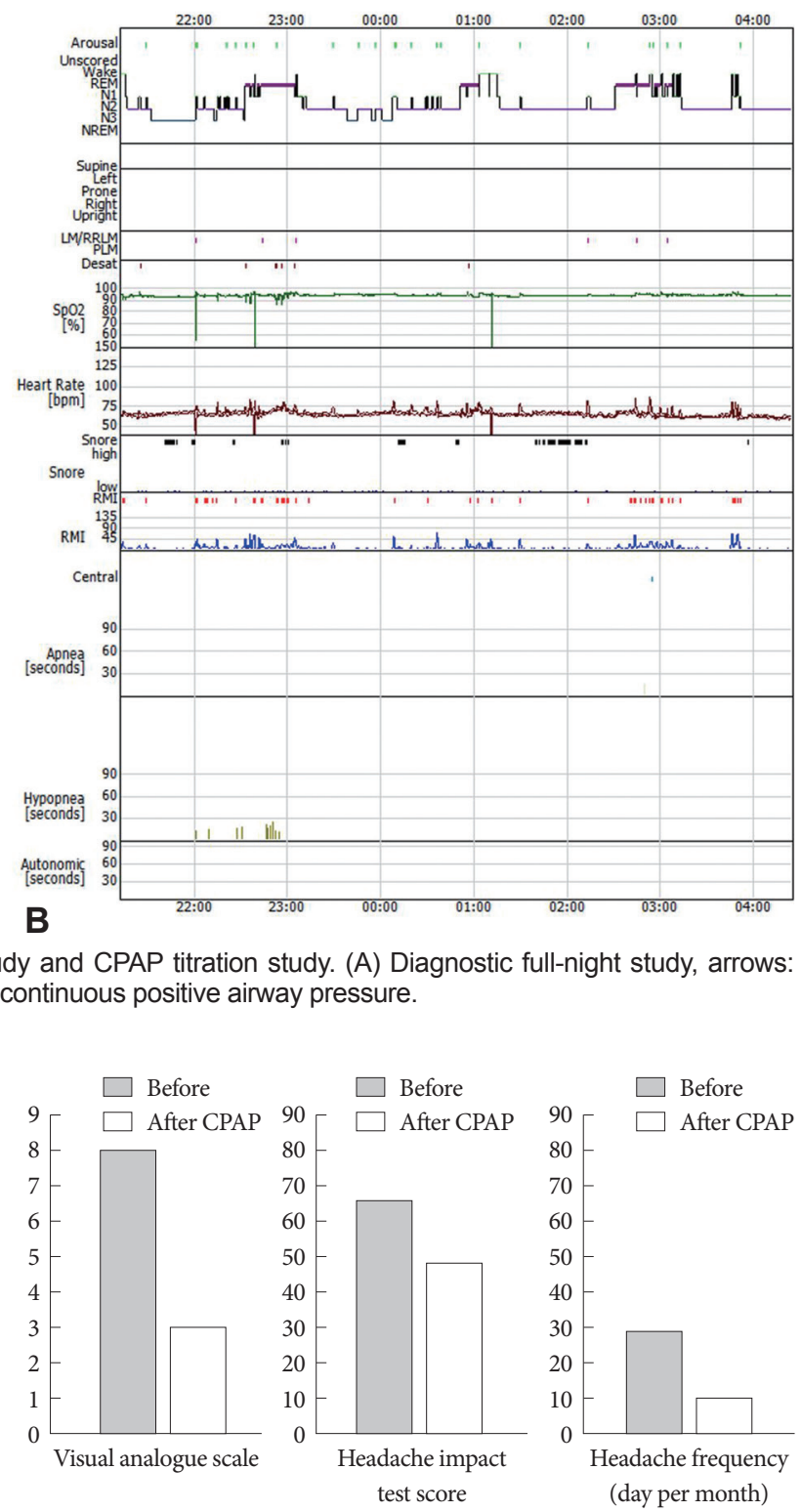

Figure 2. Improvement of the subjective intensity and frequency of the cluster headaches after 3 months of CPAP therapy. CPAP: continuous positive airway pressure.

\section{Discussion}

Headaches and sleep disorders are common and they often coexist as a disease-entity in the general population. ${ }^{3} \mathrm{CH}$ is a rare headache disorder, but one of the most painful primary headaches leading to severe disability in daily life and even depression and suicide. In its most common pattern, episodic or chronic $\mathrm{CH}$ has a periodicity, especially occurring seasonally. In the chronic phase, daily attacks at the same time or in the same time pattern is not uncommon. Nocturnal attacks of $\mathrm{CH}$ are more frequent than daytime attacks. ${ }^{4}$ REM sleep is known to be associated with $\mathrm{CH}$ attacks in certain patients with periodicity or circannual rhythm. ${ }^{5}$ Oxygen inhalation has been 
the standard of acute symptomatic relief of $\mathrm{CH}$ and evidenced to be the most effective therapy. The possible mechanism of oxygen can be explained by meningeal vasodilatation and activation of the trigeminocervical complex. ${ }^{6} \mathrm{CH}$ and OSA, one of the most common sleep disorders, share common clinical characteristics. The association between $\mathrm{CH}$ and OSA has been studied and evidenced as more likely to coexist than normal controls (about 8.4 times more).$^{7.8}$ Sleep apnea could also initiate the headaches, especially during sleep. Apnea related headaches could be caused by cerebral vasodilation related to hypoxemia or REM related hypoventilation. Oxygen supplement is the most effective option of both diseases, though different mechanism (chemoreceptor stimulation or pneumatic splint). In our case, the patient developed severe OSA with the remarkable oxygen desaturation and suffered cyclic $\mathrm{CH}$ during the night. Although improvement of $\mathrm{CH}$ with treatment of OSA does not prove a causal relationship, abolishment of hypoxia by sleep apnea alleviated the intensity and frequency of the nocturnal pain. There have been several reports of CPAP therapy in $\mathrm{CH}$ patients with OSA, ${ }^{9,10}$ but there was not a serial report of improvement of AHI or objective headache measurement after CPAP. We present a case of nocturnal $\mathrm{CH}$ that can coexist with OSA and that showed improvement of pain with successful CPAP therapy. Clinicians need to consider the possibility of comorbid OSA when managing patients with $\mathrm{CH}$ or primary headaches with a nocturnal tendency.

\section{Acknowledgments}

None.

\section{Conflicts of Interest}

The authors have no potential conflicts of interest to disclose.

\section{ORCID iDs}

Min-Jun Song

https://orcid.org/0000-0001-7416-9149
Soo-Jin Cho https://orcid.org/0000-0002-4053-3763

Hee-Jin Im https://orcid.org/0000-0002-8979-6521

\section{Author Contributions}

Conceptualization: Hee-Jin Im. Data curation: Hee-Jin Im. Formal analysis: Hee-Jin Im. Investigation: Hee-Jin Im. Methodology: Hee-Jin Im. Project administration: Hee-Jin Im. Supervision: Hee-Jin Im. Visualization: Hee-Jin Im. Writing_original draft: Min-Jun Song. Writing_review \& editing: Soo-Jin Cho, Hee-Jin Im.

\section{REFERENCES}

1. Olesen J. International classification of headache disorders. Lancet Neurol 2018;17:396-397. https://doi.org/10.1016/S1474-4422(18)30085-1.

2. Mitsikostas DD, Edvinsson L, Jensen RH, et al. Refractory chronic cluster headache: a consensus statement on clinical definition from the European Headache Federation. J Headache Pain 2014;15:79. https:// doi.org/10.1186/1129-2377-15-79.

3. Alberti A. Headache and sleep. Sleep Med Rev 2006;10:431-437. https://doi.org/10.1016/j.smrv.2006.03.003.

4. Barloese M, Jennum P, Knudsen S, Jensen R. Cluster headache and sleep, is there a connection? A review. Cephalalgia 2012;32:481-491. https://doi.org/10.1177/0333102412441090.

5. Pfaffenrath V, Pöllmann W, Rüther E, Lund R, Hajak G. Onset of nocturnal attacks of chronic cluster headache in relation to sleep stages. Acta Neurol Scand 1986;73:403-407. https://doi.org/10.1111/j.16000404.1986.tb03296.x.

6. Halker R, Vargas B, Dodick DW. Cluster headache: diagnosis and treatment. Semin Neurol 2010;30:175-185. https://doi.org/10.1055/s-00301249226.

7. Graff-Radford SB, Newman A. Obstructive sleep apnea and cluster headache. Headache 2004;44:607-610. https://doi.org/10.1111/j.15264610.2004.446010.x.

8. Nobre ME, Leal AJ, Filho PM. Investigation into sleep disturbance of patients suffering from cluster headache. Cephalalgia 2005;25:488-492. https://doi.org/10.1111/j.1468-2982.2004.00897.x.

9. Buckle P, Kerr P, Kryger M. Nocturnal cluster headache associated with sleep apnea. A case report. Sleep 1993;16:487-489. https://doi.org/ 10.1093/sleep/16.5.487.

10. Nath Zallek S, Chervin RD. Improvement in cluster headache after treatment for obstructive sleep apnea. Sleep Med 2000;1:135-138. https://doi.org/10.1016/s1389-9457(99)00010-6. 